See Article page 1050.

\section{Commentary: Positive pressure toward a negative trial?}

\author{
Todd L. Demmy, MD
}

The article in this issue of the Journal by Paleiron and colleagues ${ }^{1}$ shows that broad use of preoperative external ventilatory support for high-risk patients up to the time of surgery does not significantly reduce perioperative complications. But is this the end of the story? Probably not, and it is because of study design concerns that are very instructive for readers.

According to their planning, the designers of this trial decided to make preOVNI (Pre-operative Noninvasive Ventilation) overcome several potential hurdles to demonstrate its worth. The first was randomization, generally a good thing for dealing with selection bias. Randomization, however, also requires achievement of equipoise among investigators and participants. Equipoise, the concept that "it may or may not help," could discourage participants from adopting inconvenient therapies such as prolonged pressure mask applications. Randomization does not always achieve a desired balance of traits known to influence the primary end point and, in this study, patients who were treated thoracoscopically and typically had fewer complications were more common in the control arm. This could have been avoided by a block randomization design.

Second, this was a multicenter trial, which is a good thing for improving rates of accruals and demonstrating capability to disseminate a therapy. As in this trial, however, multicenter studies generally yield more unanticipated methodologic problems and often increase the range of adverse events. For instance, rates of respiratory complications were higher than planned. Increasing variability makes it harder for statistical tests to exclude the null hypothesis. The variability in this study also increased because

From the Department of Thoracic Surgery, Roswell Park Cancer Institute, Buffalo, NY; and Department of Surgery, University at Buffalo, Buffalo, NY.

No funding was provided for this article.

Disclosures: Author serves as a consultant for Medtronic.

Received for publication Oct 25, 2019; revisions received Oct 25, 2019; accepted for publication Oct 25, 2019; available ahead of print Nov 13, 2019.

Address for reprints: Todd L. Demmy, MD, Department of Thoracic Surgery, Roswell Park Cancer Institute, Elm and Carlton St, Buffalo, NY 14263 (E-mail: todd. demmy@roswellpark.org).

J Thorac Cardiovasc Surg 2020;160:1062-3

$0022-5223 / \$ 36.00$

Copyright (C) 2019 by The American Association for Thoracic Surgery

https://doi.org/10.1016/j.jtcvs.2019.10.141
Check for updates

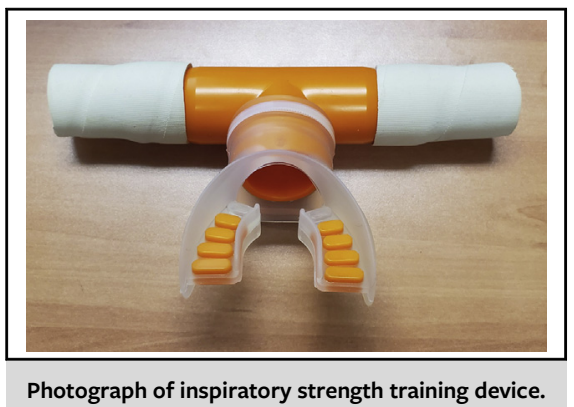

CENTRAL MESSAGE

Rigorous study design con-

straints may have made it difficult

to detect therapeutic benefits of

preoperative external ventilatory

support therapy in high-risk pul-

monary patients.

initiation of treatment and support of patients through preOVNI requires a system of respiratory provider training and support. Achieving systematic standardization and reproducibility at the 8 of 17 centers with 4 or fewer participants may have been difficult.

Third, study group selection was quite broad, which is a good thing for showing preOVNI to be widely generalizable. At least a quarter of the patients, however, were eligible because of cardiac risk factors that mechanistically may not benefit from external pressure support. Furthermore, the local investigators could alter the recommended inhaled pressure values to improve participant compliance.

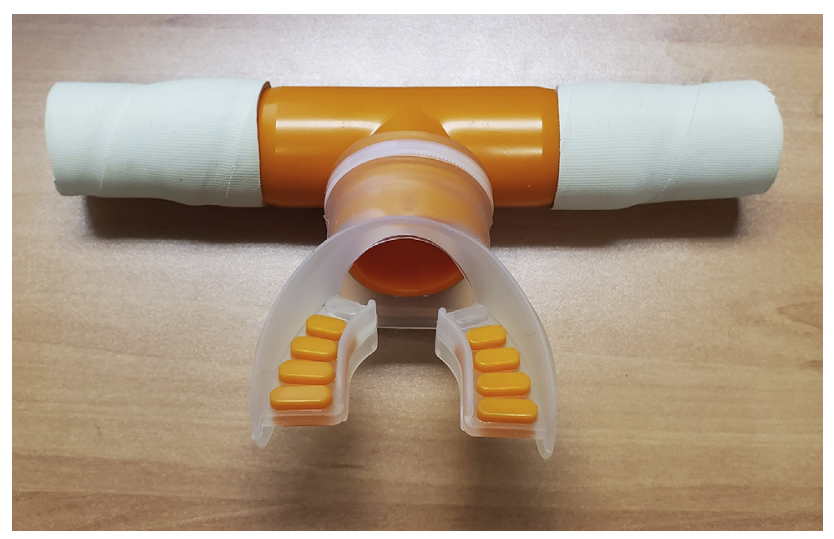

FIGURE 1. Photograph of custom-made inspiratory strength training device being used to study an alternative preoperative therapy for high-risk thoracic surgical patients. Courtesy of Dr Andy Ray. 
Finally, preOVNI ended just before the surgical perturbation expected to create adverse events relative to the primary end point. This is good in the sense of the primary intent to measure only preOVNI benefit. Perhaps, however, a therapy that has offloaded respiratory work and enhanced organ function should not stop abruptly before an episode of increased stress? In comparison, useful cardiac and renal organ support therapies are normally continued or even increased perioperatively. Stopping a therapy immediately before the operation may make better sense for a treatment designed to increase host organ reserve rather than support it. This is what is done for studying of inspiratory muscle strengthening maneuvers (Figure 1$)^{2}$

Paleiron and colleagues ${ }^{1}$ have thus shown that preOVNI without postoperative continuation should not be applied too broadly. Because of a trend toward fewer episodes of pneumonia despite the countervailing pressures of the study design noted here, a reader is justified in expecting further research in this area, particularly in more select (respiratory) populations and with continuation of potentially useful pressure support at times of greater need.

I am grateful to Dr Andrew Ray for supplying graphical content to this commentary.

\section{References}

1. Paleiron N, Grassin F, Lancelin C, Tromeur C, Margery J, Natale C, et al Assessment of preoperative noninvasive ventilation before lung cancer surgery: the pre-OVNI randomized controlled study. J Thorac Cardiovasc Surg. 2020; 160:1050-9.e3.

2. Kendall F, Oliveira J, Peleteiro B, Pinho P, Bastos PT. Inspiratory muscle training is effective to reduce postoperative pulmonary complications and length of hospital stay: a systematic review and meta-analysis. Disabil Rehabil. 2018;40:864-82. 